\title{
50 Years On Still Relevant
}

\author{
Graeme Avery ONZM, KNZM ${ }^{1}$
}

Published online: 12 December 2020

(c) Springer Nature Switzerland AG 2020

50 years ago there was a plethora of new drug introductions, but a dearth of sources of reliable, balanced information to aid rational prescribing decisions.

Drugs was introduced in 1971 to meet this need, as the international subscription edition of a successful Australasian controlled circulation continuing education journal on therapeutics, New Ethicals.

In 1970, I had met with leading drug regulatory and prescribing education leaders in the UK, Germany and the USA to seek and receive their endorsement for Drugs-a scholarly review journal that would provide independent evaluations of the best published literature supporting the pharmacological properties, efficacy, safety and appropriate clinical use of new drug products.

At the time, there was a real need for a balanced information source to bridge the gap between the biases of the promotional material of the pharmaceutical company and those with bias from a different direction of Government and other publications such as for example, the Prescribers Journal and Drugs \& Therapeutics Bulletin, in the UK and the Medical Letter in the USA.

The first step involved establishing an International Honorary Editorial Board of eminent clinicians who had demonstrated their commitment to the teaching of therapeutics and the emerging specialty of clinical pharmacology. The Board, along with other specialist experts in the field of the new drug, would play a large part in the development of Drugs by reviewing manuscripts on the detailed evaluation of new products prior to publication, and contributing review articles themselves on new drug classes and their use in therapeutics.

An editorial team of in-house clinical pharmacists was recruited globally and the skills developed to analyse, evaluate and summarise the ever increasing large volumes of data and information on each new drug. Such was the growth in

Graeme Avery ONZM, KNZM

dru@adis.com

1 Hastings, New Zealand new source publications, and to be independent in source supply from the pharmaceutical industry, that an in-house drug literature retrieval system was established to index articles on drugs and their use in disease treatment from over 1,500 world biomedical periodicals.

Pre-publication peer review of the Drug Evaluation manuscripts for Drugs was a fundamental pillar for the reputation of the independently authored and balanced reviews gained by the journal. As academic reviewers and clinical research trialists had their biases too, balance was achieved by review also from the medical department of the pharmaceutical company. Comments from all reviewers were received and interpreted for veracity and fair balance for the final publication. This thorough peer review approach served the Drug Evaluation programme well and remains so today.

Adis as the original publisher, from its headquarters in Auckland, New Zealand, because of its isolation from big pharma and big science, needed to become self-sufficient in having both access to the new scientific literature but also having the in-house skills and those of external consultants, to create new knowledge on pharmaceuticals based on world best evidence. Little did it know at the time that its highly structured summaries and interpreted results of pharmaceutical research was establishing a database of systematic reviews, and that its technique of evaluating the literature was akin to today's meta-analysis.

Adis became a world leading pioneer in definitive reviews on drugs and therapeutics, and the green journal Drugs its flagship. The editorial group of biomedical science professionals in Auckland grew to over 100 by the late 1990's and spawned a complete publishing system to support the now Adis Drug Evaluations and related scholarly review journal publications programme, which included world firsts for the journals in their specialist fields- 'Clinical Pharmacokinetics' and 'Pharmacoeconomics' being paramount.

50 years on, after more than 8700 Drug Evaluations and Reviews on Drugs, the publication retains its relevance and importance as an independent source of best evidence knowledge to support rational use of drugs in therapeutics. 
So many highly talented individuals contributed to Drugs as authors and reviewers, and in the associated development of the company and its offices at HQ in New Zealand, but also in Japan, the UK, across Europe and in the USA. May I, however, make special acknowledgement and tribute to the foundation authors who I trained-Trevor Speight, Rex Brogden and later Rennie Heel who succeeded me as Editorin-Chief. Without them and their colleagues, Drugs and the publishing company created to produce it, would never have happened. A monumental ride.

Here is to the next 50 years! It is going to be a very different ride.

\section{Declarations}

Funding No external funding support was received.

Conflicts of interest Sir Graeme Avery is responsible for the article content and has no conflicts of interest to declare. 